\title{
Determinantes Psicológicos da Intenção de Constituir Família
}

\author{
Psychological Determinants of the Intention to Constitute a Family
}

\author{
Taciano Lemos Milfont ${ }^{\mathrm{a} * *}$, Valdiney V. Gouveia ${ }^{\mathrm{b} *}$, \& Joselí Bastos da Costa ${ }^{\mathrm{b}}$ \\ ${ }^{a}$ Universidade Federal de Alagoas, ${ }^{b}$ Universidade Federal da Paraíba
}

\begin{abstract}
Resumo
Estudos têm predominantemente analisado as organizações familiares já formadas. Tentando trazer a análise a um passo anterior, este estudo investigou a intenção de constituir família, verificando em que medida algumas variáveis psicológicas (valores humanos básicos, auto-imagens independente e interdependente e atitudes frente a relações afetivas estáveis) explicam esta intenção. Participaram 658 universitários com estado civil solteiro, sendo 50,6\% do sexo feminino e com idade média de 20 anos. Apenas os valores de orientação social e as atitudes frente a relações afetivas estáveis, especificamente envolvimento e comprometimento, apresentaram correlação com a intenção de constituir família. Adicionalmente, verificou-se que apenas os valores afetividade, religiosidade e estabilidade pessoal predisseram esta intenção. As implicações destes resultados são discutidos e pesquisas futuras sugeridas.

Palavras-chave: Intenção de constituir família; valores humanos básicos; auto-imagem; relações afetivas estáveis.
\end{abstract}

\begin{abstract}
Studies have focused predominantly on family organizations that have been previously constituted. Trying to bring the analysis to a previous step, this study analyzed the intention to constitute a family, studying in which extension this intention is explained by psychological variables (basic human values, the independent and interdependent self-construals, and the attitudes toward stable affective relationships). 658 single undergraduate students participated in this study, of which $50.6 \%$ were women with a mean age of 20 years. Correlations and regressions analysis were performed. As hypothesized, the importance attributed to social values and attitudes toward stable affective relationships were correlated with the intention of constituting a family. However, neither independent nor interdependent self-construals presented significant correlations. Specifically, three values (affectivity, religiosity and personal stability) appear to be predictors of this intention. The implications of these findings are discussed, and future researches on this thematic are suggested.

Keywords: Intention to constituting a family; basic human values; self-construal; stable affective relationships.
\end{abstract}

O termo família origina-se do latim famulus, significando um conjunto de servos e dependentes de um chefe ou senhor (Prado, 1989). A família é entendida como um ponto médio entre a sociedade e o indivíduo (Freixa, 1998), sendo, pois, um dos lugares privilegiados na construção social da realidade (Sacareno, 1997). Embora presentes em toda a história da humanidade, as organizações familiares vêm se modificando ao longo do tempo, principalmente no século passado, pois as estruturas sócio-econômicas vêm mudando e os vínculos afetivos estão sendo estabelecidos de formas diferentes. Com isso, a aparição de novos modelos familiares questiona as funções e as estruturas dos modelos anteriores. O desenvolvimento da família, no entanto, aparenta ter o mesmo padrão no mundo ocidental, indo de uma família extensa para uma reduzida (nuclear, celular, conjugal); ou seja, as famílias numerosas cederam lugar à unidade conjugal íntima, privada (Lasch, 1987). A redução da família pode ser verificada em número (isto é, famílias com menos filhos), e em suas relações sociais e socializantes (Albornoz, 1983).

\footnotetext{
Apoio: Capes (bolsa de Mestrado T.L. Milfont).

* Endereço: UFPB, CCHLA, Campus I, Dept ${ }^{\circ}$ de Psicologia, Cidade Universitária, s/n, 58059900, João Pessoa, PB. Fone: (83)32167337; Fax: (83)32167064.vvgouveia@uol.com.br **milfont@hotmail.com; t.milfont@auckland.ac.nz
}

Jablonski (1996, 1998) e Freixa (1998) apresentam fatores causais dessa modificação, como, por exemplo: a modernização e a urbanização decorrentes da industrialização; o aumento da longevidade, o elogio psicossocial da individualidade e do descartável; a realização cada vez mais tardia das uniões; as mudanças dos papéis exercidos pelas mulheres e a recente possibilidade de decidir o momento e o número de filhos; o sexo deixa de estar vinculado à procriação e o matrimônio se dissocia da família; e o divórcio é introduzido como uma opção aceitável.

Verificam-se, pois, mudanças fundamentais nos modelos familiares e nos vínculos de outrora aos de agora (Freixa, 1998): do matrimônio legal à possibilidade da união consensual; do matrimônio vitalício à possibilidade do divórcio; do sexo como função procriadora ao sexo como prazer; da finalidade de ter filhos(as) à finalidade de ser feliz; das relações desiguais entre homens e mulheres às relações simétricas; da função econômica exclusiva do homem para uma divisão desta função entre o casal (ou mesmo exclusivamente da mulher, Fleck \& Wagner, 2003); e de uma estrutura tradicional de família (pai, mãe e filhos/ filhas) para diferentes estruturas. Dentre as quais: família uniparental; família pluriparental ou reconstituída (formada 
pela união de pessoas divorciadas); família homossexual; famílias nas quais os parceiros decidem não procriar; e famílias formadas por casais que não possuem nenhum vínculo legal.

Mesmo existindo uma grande produção acadêmica sobre esta temática (Ex.: Goldani, 1994; Löhr \& Wasch, 1992; Macedo et al., 2000), não foi encontrado nenhum trabalho que verificasse quais as variáveis psicológicas que podem explicar a intenção de constituir família. O presente estudo se propõe a dar uma primeira contribuição neste sentido. Portanto, faz-se necessário considerar mais detidamente o que se entende por intenção de constituir família.

\section{A Intenção de Constituir Família}

Osório (1996) define três estágios no ciclo vital de uma família: expansão, referente à formação de um casal para a construção de uma nova família e/ou nascimento e adolescência dos filhos; dispersão, compreendendo a saída dos filhos de casa e/ou divórcio/separação dos cônjuges; e substituição, referente à morte dos avós, envelhecimento, doença e morte dos pais e/ou formação de novos núcleos familiares. Esta pesquisa centrou-se no ciclo da expansão, especificamente na constituição da família.

Antes havia um maior controle no ingresso ao matrimônio, pois os casamentos eram "arranjados" pelos pais, constituindo-se muito mais em vínculos contratuais do que afetivos. A partir do Século XIX, o casamento torna-se uma união de indivíduos em vez de apenas uma união de duas linhagens, haja vista os jovens já terem conquistado o direito de casar-se com um mínimo de interferência direta dos pais (Lasch, 1987). A esse respeito Goode (1969) afirma que "mesmo sem dados adequados que nos orientem na compreensão desta mudança, parece provável que as características sociais das origens de família exercem agora menor papel na escolha do consorte, e um papel maior, as características dos indivíduos que se querem casar” (p.43; grifos no original).

A influência dos sistemas industrial e capitalista parece marcante quando se analisa a constituição familiar. A família pressupõe um nós (união de duas pessoas) e a filosofia liberal valoriza e exacerba o eu. Ou seja, mesmo sendo necessária uma identidade conjugal, conseguida através das interações das pessoas que decidem constituir uma família, os ideais contemporâneos enfatizam a autonomia e a satisfação de cada um, nos seus planos e nas aspirações de vida (FéresCarneiro, 1998). Uma vez que quanto mais livre esteja a pessoa, ou seja, sem estar presa a laços familiares, maior será sua mobilidade ocupacional e geográfica. Por conseguinte, esta maior autonomia e mobilidade físicoafetiva poderá ser usada para suprir as necessidades da industrialização e não as necessidades familiares ou individuais (Carneiro, 1994; Goode, 1969).

Pinheiro e Tamayo (1987), ao analisar estudos sobre urbanização e solidão, verificaram que a vida urbana diminui os contatos primários entre as pessoas, sendo estes substituídos por contatos secundários e impessoais. Ou seja, atualmente as pessoas vivem mais próximas uma das outras nos grandes centros urbanos, porém vivem isoladas, buscando privacidade. Como exemplo, pode-se analisar a tendência mundial a se viver só. No Brasil, $9 \%$ dos domicílios já são ocupados por uma só pessoa (Veiga, 2001). Verificase, pois, que a individualização, a cultura do "cada um por si”, é marcada pela falência de referenciais e está modificando o modo como as pessoas agem e se relacionam umas com as outras, provocando grandes dificuldades para o estabelecimento de vínculos afetivos duradouros.

Os estudos em Psicologia freqüentemente analisam a família já formada, ficando a sua constituição como um aspecto intocável, evidente, dado por si só. Melhor dizendo, talvez não se tenha dado atenção à constituição familiar por ser considerado um fenômeno social que invariavelmente ocorre, bastando apenas aguardar a sua concretização para, a partir desta, e só a partir desta concretização, tomar a família como objeto de análise. Neste sentido, parece importante tratá-la antes de sua formação, considerando quais os aspectos psicológicos explicativos da intenção de constituir família.

Centrando-se nesta temática, o presente estudo buscou verificar as contribuições de três variáveis psicológicas como explicativas da intenção de constituir família. Decidiu-se utilizar os construtos valores humanos, auto-imagem e atitudes frente a relações afetivas estáveis como aspectos explicativos dessa intenção, que serão tratados a seguir.

\section{Variáveis Explicativas da Intenção de Constituir Família Valores humanos}

Muitas são as contribuições teóricas ao tema dos valores (para uma revisão, ver Gouveia, 1998; Milfont, 2001), mas no presente estudo decidiu-se utilizar a proposta dos Valores Humanos Básicos elaborada por Gouveia (1998, 2003) por três motivos principais: 1) esta proposta segue uma abordagem bastante consolidada, a qual assume os valores como representações das necessidades humanas (Rokeach, 1973; Schwartz, 1994); 2) evidencia uma estruturação teórica quando da eleição de cada um dos valores; e, 3) apresenta parcimônia, já que estudos empíricos têm demonstrado a possibilidade de utilizá-la em substituição aos Tipos Motivacionais propostos por Schwartz (Gouveia, 2003; Meira, Gouveia, Maia, Nunes Jr., \& Andrade, 2001), com o ganho de possuir um número menor de valores.

A partir das necessidades postuladas por Abraham Maslow (1954), Gouveia (1998) estipula a existência de 24 valores básicos que representam as necessidades humanas. Todos os valores são terminais, expressando um substantivo, e organizam-se em três grandes grupos, segundo o critério de orientação que a pessoa adota, os quais dão origem a seis funções psicossociais: Pessoal (existência, experimentação e realização), Social (interacionais e normativas) e Suprapessoal ${ }^{1}$.

\footnotetext{
${ }^{1}$ Esta é a versão do modelo que foi utilizada no presente estudo, pois o modelo sofreu algumas modificações. Ver a descrição da versão atual em Gouveia (2003) e Gouveia, Vasconcelos, Queiroga, França, e Oliveira (2003).
} 
As características destes padrões valorativos são:

- Valores Suprapessoais. As pessoas que adotam este critério de orientação valorativa não se limitam às características descritivas ou consideram traços específicos para começar uma relação ou proporcionar benefícios. Descreve alguém maduro, sem apegos materiais e que procura alcançar seus objetivos independentemente da sua condição social ou grupo afiliativo;

- Valores Sociais. As pessoas guiadas por estes valores se orientam em direção aos demais, adotando comportamentos que traduzem o desejo de se sentirem consideradas, aceitas e integradas ao grupo. Sua subdivisão psicossocial normativo coloca ênfase na vida social, na busca de estabilidade e ordem do grupo, além de respeitar os símbolos e padrões culturais que prevaleceram durante anos. A outra subdivisão, interacional, é privilegiada por pessoas que fundamentam seus interesses em sentirem-se queridas, terem uma amizade verdadeira e uma vida social ativa; e,

- Valores Pessoais. Quem assume este padrão valorativo costuma manter relações pessoais de tipo contratual, geralmente com o fim de obter benefícios próprios. Seus valores de existência expressam uma preocupação de garantir a própria existência orgânica. Os de experimentação enfatizam o fato de descobrir e apreciar novos estímulos, enfrentar situações limite, além de buscar satisfação sexual. Os valores de realização caracterizam o sentimento de ser importante e poderoso, ser uma pessoa com identidade e espaço próprio.

Estudos têm relacionado os valores às organizações familiares (Ex.: ver Azzi, 1987; Wagner, Falcke, \& Meza, 1997), especialmente com relação à socialização humana e à manutenção dos sistemas de valores, pois é principalmente nesta instituição que as crianças os internalizam (Bell \& Vogel, 1963; Cárdenas, 1996; Molpeceres, 1994; Neder, 1994; Schneider, 2001). Todavia, a relação entre valores e organizações familiares apresenta outra dimensão no presente estudo. De acordo com Tamayo e Schwartz (1993), um dos temas freqüentes das pesquisas sobre os valores é a tentativa de relacioná-los com atitudes e padrões de comportamento. Buscou-se, pois, verificar como as prioridades axiológicas explicam a intenção de constituir família.

\section{Auto-imagem}

O estudo do self não é recente nas Ciências Humanas e Sociais, constituindo um dos aspectos mais centrais destas áreas do conhecimento, a saber: a relação indivíduosociedade (Kuhn \& McPartland, 1954). Várias pesquisas vêm focalizando o papel das relações entre os indivíduos para a construção, avaliação e manutenção do self, além do papel dos outros indivíduos como partes interdependentes deste (Biaggio, 1996; Trafimow, Triandis, \& Goto, 1991). Na perspectiva das relações sociais é que este constructo vem sendo estudado em diferentes culturas, principalmente a partir dos estudos sobre o individualismo e o coletivismo (Hofstede, 1984; Triandis, 1994, 1995). Com base nesses construtos, Markus e Kitayama (1991) propõem um modelo dual de self, denominado self-construal ou auto-imagem. Este modelo pode ser concebido como uma constelação de pensamentos, sentimentos e ações reunidas em duas dimensões, auto-imagem independente e interdependente, descritas nos seguintes termos (ver, também, Gouveia, Singelis, \& Coelho, 2002; Singelis, 1994):

- Auto-Imagem Independente. Define-se como um selfestável, unitário e delimitado, separado do contexto social. Os elementos enfatizados por este tipo de self são: habilidades, pensamentos e emoções internas; ser único e expressar a si mesmo; realizar os atributos internos e perseguir os próprios objetivos; e uma comunicação direta;

- Auto-Imagem Interdependente. Define-se como flexível e variável, enfatizando traços externos e públicos, tais como: o status, os papéis exercidos e relacionamentos; pertencer e ajustar-se; ocupar lugar adequado e engajar-se em ações apropriadas; e comunicação indireta.

Alguns autores vêm relacionando as concepções de individualismo/coletivismo e independente/ interdependente com as organizações familiares. Por exemplo, os modelos de família propostos por Kagitçibasi (1994) e a Family Allocentrism Scale proposta por Lay et al (1998), são úteis para estudar as interações dos membros da família, as estruturas familiares e os processos de socialização infantil. No entanto, tratam a família já constituída, não trazendo contribuições para o tipo de estudo aqui proposto.

Estudos têm demonstrado, por outro lado, que o construto de self dual pode ser utilizado em amplos aspectos das relações sociais, pois os fatores que caracterizam a autoimagem das pessoas, se conectadas (auto-imagem interdependente) ou separadas (auto-imagem independente) das demais, possuem poder explicativo em âmbitos diversos (Markus, \& Kitayama, 1991). Assim, este construto tem sido utilizado como explicação de vários fatores, tais como o processo de comunicação (Singelis \& Brown, 1995), o contágio emocional (Singelis \& Sharkey, 1995), o sentimento de constrangimento (Gouveia, Singelis, Guerra, Santos, \& Vasconcelos, 2005; Singelis \& Sharkey, 1995), a moralidade (Espinosa, 2000), as relações interpessoais (Gouveia, Coelho, \& Vasconcelos, 1999), além das suas relações com os valores humanos (Milfont, Gouveia, Chaves, Socorro, \& Queiroga, 2002; Oishi, Schimmack, Diener, \& Suh, 1998). Neste sentido, a auto-imagem é tratada como uma variável explicativa da intenção de constituir família.

\section{Atitudes frente a relações afetivas estáveis}

Thomas e Znaniecki (1918/1984) introduzem o termo atitude em Psicologia Social. As atitudes são "uma organização duradoura de crenças e cognições em geral, dotada de carga afetiva pró ou contra um objeto social definido, que predispõe a uma ação coerente com as cognições e os afetos relativos a este objeto" (Rodrigues, Assmar, \& Jablonski, 2000, p.100). As atitudes são variáveis latentes, não sendo diretamente observáveis mas inferidas de observações, podendo ser medidas através destas observações a ela relacionadas (Anastasi \& Urbina, 2000; Lima, 1996; Rodrigues et al., 2000). Não existe nenhum 
outro tema em Psicologia Social cujas pesquisas sejam mais numerosas (Montmollin, 1985), principalmente no que concerne à sua mensuração (Anastasi \& Urbina, 2000). Porém, as técnicas de medição existentes geralmente buscam mensurar uma das dimensões de cada vez: o componente comportamental podendo ser medido pelas escalas de observação, o afetivo através das medidas psicofisiológicas e o cognitivo pelas escalas psicométricas (Clemente \& Fernández, 1992).

Ao abordar as atitudes, este estudo centrou-se no componente cognitivo, utilizando uma escala de resposta do tipo Likert. Estas produzem um escore total indicando a direção e a intensidade da atitude dos indivíduos em relação à categoria de estímulo (Anastasi \& Urbina, 2000). Neste sentido, foram medidas as atitudes frente a relações afetivas estáveis (Bystronski, 1991; Reis, 1995), pois considera-se que estas influenciam a intenção de constituir família.

Desta forma, o objetivo da presente pesquisa foi analisar em que medida as variáveis valores humanos, auto-imagem (independente interdependente) e atitudes frente a relações afetivas estáveis explicam a intenção de constituir família.

\section{Método}

\section{Delineamento e Hipóteses}

Tratou-se de um estudo correlacional com as seguintes hipóteses:

- Valores Humanos. A intenção de constituir família está diretamente correlacionada à importância atribuída aos valores sociais (Hipótese 1); a intenção de constituir família está inversamente correlacionada com à importância atribuída aos valores pessoais (Hipótese 2); e a intenção de constituir família não está correlacionada à importância atribuída aos valores suprapessoais (Hipótese 3).

- Auto-Imagem. As pontuações na auto-imagem interdependente estão diretamente correlacionadas à intenção de constituir família (Hipótese 4); e as pontuações na auto-imagem independente estão inversamente correlacionadas à intenção de constituir família (Hipótese 5).

- Atitudes frente a relações afetivas estáveis. As atitudes frente a relações afetivas estáveis estão diretamente correlacionadas à intenção de constituir família (Hipótese 6).

\section{Amostra}

Este estudo foi realizado com uma amostra intencional, não-probabilística. Foram aplicados 711 questionários a calouros universitários das três áreas do conhecimento (Saúde, Humanas e Exatas), provenientes de duas universidades de Pernambuco, Brasil, sendo uma pública e outra privada. O critério de inclusão na amostra foi o estado civil solteiro e o correto preenchimento do questionário por parte dos respondentes. Seguindo estes critérios, 53 questionários foram eliminados, totalizando $8 \%$ dos questionários aplicados, restando, portanto, 658 questionários válidos. A idade dos participantes variou entre 17 e 42 anos $(m=19,9 ; d p=2,5)$, sendo distribuídos eqüitativamente quanto ao sexo. A maioria dos estudantes era da religião Católica (69,8\%), sendo que 15,3\% afirmaram não possuir nenhuma religião.

\section{Instrumentos}

Os participantes responderam a um questionário composto por seis partes:

- Informações Gerais. Informações sobre o objetivo e a confidencialidade do estudo, além de algumas orientações para o correto preenchimento dos questionários.

- Questionário dos Valores Humanos Básicos. Composto por 24 itens que procuram avaliar quais os valores que orientam a vida das pessoas (Gouveia, 1998). Os respondentes expressam o grau de importância de cada valor como princípio-guia em suas vidas através de uma escala de sete pontos, indo de 1 (Nada Importante) a 7 (Muito Importante). Maia (2000) e Gouveia (2003) apresentam informações sobre sua validade e precisão.

- Escala de Auto-Imagem (EAI). Elaborada e validada por Singelis (1994) com amostra estadunidense, esta escala obteve Alfa de Cronbach de 0,74 e 0,70 para as sub-escalas de auto-imagem interdependente e independente, respectivamente. Os índices de consistência interna no Brasil foram 0,54 para a auto-imagem interdependente $\mathrm{e}$ 0,52 para a independente (Gouveia et al., 2002). Os respondentes expressam seu grau de concordância para os 24 items através de uma escala de sete pontos, tipo Likert, que vai de 1 (Discordo Fortemente) a 7 (Concordo Fortemente). No presente estudo os índices de consistência interna foram 0,57 e 0,50 para auto-imagem interdependente e independente, respectivamente.

- Escala de Atitudes Frente a Relações Afetivas Estáveis (RAE). Esta medida é composta por 30 itens, respondidos em uma escala de cinco pontos, tipo Likert, indo de 1 (Absolutamente Dispensável) até 5 (Absolutamente Indispensável), tendo o objetivo de verificar as atitudes favoráveis a relações afetivas estáveis. Desenvolvida por Reis (1995), foi validada no Brasil e nos Estados Unidos da América, obtendo alta fidedignidade em ambas as amostras (alpha=0,91 e 0,89, respectivamente). No estudo de sua validação (ver Bystronski, 1991; Reis, 1995), no entanto, esta medida apresentou a possibilidade de uma estrutura multidimensional. Por isso, decidiu-se realizar uma análise fatorial (ver Milfont, 2001; Milfont, Gouveia, Jesus, Gusmão, \& Chaves, 2001). Resumidamente, os fatores encontrados foram: Edificação (alpha=0,78), Comprometimento (alpha=0,84), Envolvimento (alpha=0,72), Mutualidade (alpha $=0,80)$ e Indulgência (alpha $=0,72)$. Tratados em conjunto, os itens da escala também apresentam consistência interna adequada (alpha $=0,92)$.

- Intenção de constituir família. Avaliado através de um item, pediu-se aos respondentes que indicassem em uma escala de cinco pontos, indo de 1 (baixa intenção) até 5 (alta intenção), qual a probabilidade de constituírem família nos próximos 10 anos.

- Questionário Sócio-demográfico. Composto por 19 itens, buscou caracterizar a amostra, obter informações sobre a 
constituição da família de origem dos respondentes e o tipo de família que pretendem constituir.

\section{Procedimento}

Após a autorização das universidades para a realização da coleta dos dados, o primeiro autor administrou os questionários, informando os objetivos da pesquisa e fornecendo as instruções para o correto preenchimento dos instrumentos. Os questionários foram respondidos individualmente pelos universitários, mas em situação coletiva de sala de aula, tendo sido necessários, em média, 20 minutos para o seu preenchimento. Com exceção da primeira e última parte do questionário, as demais foram contrabalançadas, procurando evitar o efeito de exposição da informação e possível viés de resposta.

\section{Resultados}

\section{Análises Preliminares}

No momento da pesquisa, a maioria dos estudantes (42,7\%) estava sem ninguém, $38,5 \%$ estavam namorando fixo, 15,8\% com namorado(a) ocasionais e $3 \%$ noivos(as). Sobre suas opções sexuais, a grande maioria indicou ser heterossexual $(97,4 \%)$ - com o aparecimento pequeno de estudantes com orientações homossexuais e bissexuais (0,9\% e 0,6\%, respectivamente), e com $1,1 \%$ preferindo não indicar a orientação sexual.

Com relação às suas famílias de origem, no momento da realização da pesquisa a maioria morava com os pais $(81,3 \%)$ e estes se encontravam casados/conviventes (71,9\%), e $40,1 \%$ dos participantes possuíam dois irmãos/irmãs. No que se refere às famílias que pretendem ter, a maioria $(73,4 \%)$ pensava em legitimar a união com matrimônio civil e religioso; $13,4 \%$ apenas matrimônio civil; $10,3 \%$ pensavam em uma união livre, sem contrato legal algum; e 2,1\% apenas matrimônio religioso. Além disso, a maioria pretendia ter dois filhos $(61,9 \%)$ e se imaginavam passando o resto da vida com uma mesma pessoa $(87,8 \%)$.

Resultados das medidas de tendência central (média, mediana e moda) indicaram existir um intervalo de aproximadamente 10 anos entre as idades médias dos respondentes e as idades médias que eles pensam em constituir família, corroborando o item relativo à intenção de constituir família. Considerando-se a escala de resposta empregada para este item, a pontuação teórica mínima (baixa intenção) e máxima (alta intenção) dos participantes é de 1 a 5 , respectivamente. Os resultados indicaram uma média de $1,8(d p=0,87)$. Esta pontuação média é estatisticamente inferior à mediana teórica da escala, situada em 3 pontos $[t(627)=-33,43 ; p<0,001]$. Portanto, considerando-se esta medida, os participantes apresentaram, em geral, uma baixa intenção de constituir família nos próximos 10 anos.

\section{Variáveis Explicativas da Intenção de Constituir Família: Correlações}

As correlações da intenção de constituir família com as variáveis psicológicas são apresentadas de acordo com as hipóteses formuladas, como pode ser visto na Tabela 1.
A intenção de constituir família apresentou correlação direta e significativa $(p<0,01)$ com os valores sociais $(r=0,14)$ e não apresentou correlação com os valores suprapessoais ( $r=-0,01 ; p<0,05)$, confirmando as Hipóteses 1 e 3 , respectivamente. Não obstante, a Hipótese 2 não foi confirmada, já que não houve correlação inversa e significativa entre a intenção de constituir família e os valores pessoais $(r=0,05 ; p<0,05)$. Quanto às funções psicossociais, uma vez mais, a Hipótese 1 foi respaldada, pois houve predominância de correlação com as duas funções psicossociais, interacional e normativo $(r=0,12$ e 0,11 , respectivamente; $p<0,01$ para ambos), que compõem os valores sociais. Porém, a intenção de constituir família também se correlacionou significativamente $(p<0,01)$ com a função psicossocial existência $(r=0,12)$, que pertence aos valores de orientação pessoal. Especificamente, a intenção de constituir família apresentou correlações diretas e significativas com os valores afetividade $(r=0,18, p<0,01)$, estabilidade pessoal $(r=0,13, p<0,01)$, religiosidade $(r=0,13$, $p<0,01)$, sobrevivência $(r=0,10, p<0,01)$, obediência $(r=0,09$, $p<0,05)$ e convivência $(r=0,07, p<0,05)$.

Mesmo havendo uma correlação inversa entre a intenção de constituir família e a auto-imagem independente, a Hipótese 5 não pôde ser confirmada, pois, a correlação não foi significativa. A Hipótese 4 também não foi confirmada já que a correlação foi oposta, e não significativa, entre a intenção de constituir família e auto-imagem interdependente. Por outro lado, confirmou-se a Hipótese 6 pois houve correlação entre as atitudes frente a relações afetivas estáveis (soma total dos itens) e a intenção de constituir família $(r=0,08, p<0,05)$. Considerando a medida de atitudes frente a relações afetivas estáveis como multidimensional, observou-se correlações diretas e significativas com dois dos seus cinco fatores específicos: comprometimento $(r=0,10$, $p<0,01)$ e envolvimento $(r=0,09, p<0,05)$.

\section{Variáveis Explicativas da Intenção de Constituir Família: Regressão Múltipla}

Como os coeficientes de correlação tendem a apresentar significância com uma amostra ampla, e por não se identificar estudos prévios que permitam uma elaboração teórica a respeito, decidiu-se realizar uma regressão linear múltipla por etapas (stepwise) com o objetivo de definir o conjunto de melhores preditores da intenção de constituir família. Embora tenham sido estabelecidas hipóteses específicas, decidiu-se renunciar às indicações teóricas para definir o conjunto de preditores de tal intenção. Concretamente, as variáveis antecedentes foram selecionadas para entrar na análise de regressão com base em critério estritamente empírico: significância do coeficiente de correlações, como demonstrado na Tabela 1. Os resultados desta análise são apresentados na Tabela 2.

Das variáveis tratadas como antecedentes, incluindo seis valores humanos (religiosidade, obediência, afetividade, convivência, sobrevivência e estabilidade pessoal) e dois fatores das atitudes frente a relações afetivas estáveis (comprometimento e envolvimento), unicamente os valores 
Tabela 1

Correlações entre os Valores Humanos Básicos, as Auto-Imagens Interdependente e Interdependente, as Atitudes frente a Relações Afetivas Estáveis e a Intenção de Constituir Família $(N=658)$

\begin{tabular}{|c|c|c|c|}
\hline \multirow[t]{2}{*}{ Variável } & \multicolumn{3}{|c|}{ Intenção de Construir uma Família } \\
\hline & $m$ & $d p$ & $r$ \\
\hline \multicolumn{4}{|l|}{ Valores Humanos } \\
\hline Suprapessoal & 5,9 & 0,83 & $-0,01$ \\
\hline sabedoria & 5,9 & 1,22 & $-0,03$ \\
\hline beleza & 4,6 & 2,13 & 0,01 \\
\hline maturidade & 6,6 & 0,80 & 0,05 \\
\hline Normativo & 5,5 & 1,04 & $0,11^{*} *$ \\
\hline religiosidade & 5,5 & 2,40 & $0,13^{*} *$ \\
\hline ordem social & 6,5 & 1,01 & $-0,01$ \\
\hline tradição & 3,8 & 2,30 & 0,02 \\
\hline obediência & 6,2 & 1,08 & 0,09 *** \\
\hline Interacional & 6,1 & 0,74 & $0,12^{*} * *$ \\
\hline honestidade & 6,9 & 0,85 & $-0,02$ \\
\hline Pessoal & 8,6 & 1,01 & 0,05 \\
\hline Existência & 6,4 & 0,77 & $0,12^{*} * *$ \\
\hline sobrevivência & 6,3 & 1,10 & $0,10^{* * *}$ \\
\hline saúde & 6,4 & 1,05 & 0,01 \\
\hline estabilidade pessoal & 6,4 & 1,12 & $0,13^{*} *$ \\
\hline Experimentação & 5,3 & 1,02 & $-0,02$ \\
\hline emoção & 4,3 & 2,08 & 0,00 \\
\hline estimulação & 5,6 & 1,33 & $-0,02$ \\
\hline sexual & 5,1 & 1,91 & $-0,01$ \\
\hline prazer & 6,1 & 1,27 & $-0,04$ \\
\hline \multicolumn{4}{|l|}{ Auto-imagem } \\
\hline independente & 5,1 & 0,75 & $-0,03$ \\
\hline
\end{tabular}

\begin{tabular}{|c|c|c|c|c|c|c|c|}
\hline \multicolumn{8}{|l|}{$\begin{array}{l}\text { Atitudes frente a relações } \\
\text { afetivas estáveis }\end{array}$} \\
\hline edificação & & & 4,1 & 0,55 & & 0,01 & \\
\hline comprometimento & & & 4,6 & 0,45 & & $0,10^{* *}$ & \\
\hline envolvimento & & & 4,0 & 0,55 & & $0,09^{* *}$ & \\
\hline mutualidade & & & 4,1 & 0,55 & & 0,05 & \\
\hline indulgência & & & 4,1 & 0,54 & & $-0,01$ & \\
\hline $\begin{array}{l}\text { Somas dos itens } \\
\text { da escala RAE }\end{array}$ & & & 4,2 & 0,42 & & $0,08^{*}$ & \\
\hline \multicolumn{8}{|c|}{$\begin{array}{l}\text { Nota: }{ }^{*} p<0,05 ; * * p<0,01 . \text { Teste de significância uni-caudal, com eliminação dos casos em branco }(\text { missing) através do } \\
\text { método pairwise. As correlações em negrito são relativas às hipoteticamente esperadas. }\end{array}$} \\
\hline \multicolumn{8}{|c|}{$\begin{array}{l}\text { Tabela } 2 \\
\text { Regressão Múltipla para a Intenção de Constituir Família }(N=658)\end{array}$} \\
\hline Variáveis & $R$ & $R_{\text {ajustado }}^{2}$ & $F$ & $\operatorname{Sig}(F)$ & Beta & $t$ & $P$ \\
\hline Afetividade & 0,18 & 0,03 & $\mathrm{~F}(1 ; 624)=20,4$ & 0,001 & 0,15 & 3,81 & 0,001 \\
\hline Religiosidade & 0,21 & 0,04 & $\mathrm{~F}(2 ; 623)=14,3$ & 0,001 & 0,10 & 2,55 & 0,011 \\
\hline Estabilidade pessoal & 0,23 & 0,05 & $\mathrm{~F}(3 ; 622)=11,5$ & 0,001 & 0,09 & 2,35 & 0,019 \\
\hline
\end{tabular}

Nota: Eliminação dos casos em branco (missing) através do método pairwise. Método stepwise.

afetividade, religiosidade e estabilidade pessoal fizeram parte da equação de regressão. Estas variáveis explicaram conjuntamente $5 \%$ da variância total $\left(\mathrm{R}^{2}{ }_{\text {ajustado }}\right)$ na determinação da intenção de constituir família, sendo o valor afetividade a variável mais importante neste modelo.

\section{Discussão}

O objetivo principal deste estudo foi verificar em que medida os valores humanos, as auto-imagens independente e interdependente e as atitudes frente a relações afetivas 
estáveis explicam a intenção de constituir família. Os resultados corroboraram parcialmente as hipóteses. Apenas os valores de orientação sociale as atitudes frente a relações afetivas estáveis, especificamente envolvimento e comprometimento, apresentaram correlação com a intenção de constituir família. Adicionalmente, verificou-se que apenas os valores afetividade, religiosidade e estabilidade pessoal predisseram esta intenção.

As pessoas guiadas por valores sociais orientam-se em direção aos demais, adotando comportamentos que traduzem o desejo de se sentirem consideradas, aceitas e integradas ao grupo. Destes, correlacionaram-se com a intenção de constituir família religiosidade, obediência, afetividade e convivência. As pessoas que assumem o padrão valorativo pessoal costumam manter relações pessoais de tipo contratual, geralmente com o fim de obter benefícios próprios. Contrariando o hipoteticamente esperado, os valores pessoais não apresentaram correlação inversa com a intenção de constituir família; ao contrário, os valores sobrevivência e estabilidade pessoal apresentaram correlações diretas e significativas com esta intenção. Estes dois valores pertencem à função psicossocial de existência, indicando que, ao menos na amostra considerada, constituir família significa garantir a própria existência; esta sendo entendida aqui em termos mais amplos. Finalmente, as pessoas que adotam critério de orientação suprapessoal não se limitam às características descritivas ou consideram traços específicos para começar uma relação, descrevendo alguém maduro, sem apegos materiais e que procura alcançar seus objetivos independentemente da sua condição social ou grupo afiliativo. Os valores deste critério não justificam uma possível correlação com a intenção de constituir família, o que era hipoteticamente esperado.

Os resultados contrariaram os teoricamente esperados com relação às auto-imagens independente e interdependente, permitindo duas análises: a teoria apresenta alguma falha (ou não é adequada para o contexto brasileiro) e/ou o instrumento utilizado não permite contemplar a teoria. $\mathrm{O}$ construto de self dual apresenta formulações teóricas consistentes (Markus \& Kitayama, 1991), mas talvez em culturas com orientação intermediária entre o individualismo e o coletivismo (Hofstede, 1984), como são os casos do Brasil e da Espanha, as diferenças entre os tipos de auto-imagem não são evidenciadas (Espinosa, 2000). Isto sugere que elementos individualistas e coletivistas podem coexistir dentro de uma mesma cultura ou pessoa (Kagitçibasi, 1996; Schwartz, 1990; Sinha, \& Tripathi, 1994). Assim, dado o conjunto de dados que suportam este modelo teórico, principalmente no contexto norte-americano (Sato \& Cameron, 1999; Singelis, 1994; Singelis \& Brown, 1995; Singelis \& Sharkey, 1995), a segunda alternativa parece mais plausível. A Escala de Auto-Imagem não apresentou índices satisfatórios nos indicadores para a solução fatorial. Apesar deste aspecto, procedeu-se a tal análise, tendo-se encontrado fatores com índices de consistência interna baixos, embora aceitáveis e coerentes com aqueles encontrados em amostras brasileiras (Gouveia et al., 2002). Neste sentido, os resultados indicam a necessidade de desenvolver novos itens que venham a melhorar os parâmetros desta medida ou mesmo considerar estruturas fatoriais alternativas (Hardin, Leong, \& Bhagwat, 2004; Milfont, 2005).

Como última hipótese, esperava-se que as atitudes frente a relações afetivas estáveis estivessem diretamente correlacionadas com a intenção de constituir família. Como pôde ser visto, esta hipótese foi corroborada, sugerindo ser fundamental para a constituição familiar a construção de um relacionamento afetivo estável. Considerando a estrutura multifatorial da medida de atitudes frente a relações afetivas estáveis, apenas dois fatores (comprometimento e envolvimento), dos cinco encontrados, apresentaram correlação com a intenção de constituir família. Contudo, ambos apresentaram índices de correlação mais altos do que a correlação encontrada ao considerar essa medida como unifatorial, tal como sugeriu sua autora (Bystronski, 1991; Reis, 1995).

Sumariamente, os índices de correlação mostraram que as pessoas que priorizam como princípios-guia de suas vidas os valores de orientação social e que também valorizam, dentre outros aspectos, a confiança, a sinceridade, o respeito, a busca contínua de satisfação do outro e a intimidade em uma relação afetiva, tendem a apresentar maior intenção de constituir família. Neste sentido, o padrão de orientação destes jovens é bastante coerente, possivelmente sugerindo serem dirigidos por princípios religiosos, com uma educação que deve enfocar a dependência da dimensão afetiva, tal como o Padrão X de família descrito por Kagitçibasi (1994).

Por outro lado, os resultados da análise de regressão demonstraram que apenas os valores afetividade, religiosidade e estabilidade pessoal explicaram satisfatoriamente a intenção de constituir família. Como estes valores representam a necessidade de segurança e amor/pertença (Gouveia, 1998, 2003), os resultados sugerem que as pessoas tendem a buscar a satisfação dessas necessidades através da constituição familiar.

$\mathrm{O}$ valor afetividade (ter uma relação de afeto profunda $e$ duradoura; ter alguém para compartilhar seus êxitos e fracassos) apresentou a maior correlação com a intenção de constituir família. Este valor representa a necessidade de amor/ pertença, correspondendo à esfera mais íntima da vida social, e podendo ser entendido como um princípio-guia das pessoas que buscam relações interpessoais seguras e satisfatórias, como as que geralmente se esperam encontrar com a constituição familiar.

O valor religiosidade (crer em Deus como o salvador da humanidade; cumprir a vontade de Deus) representa a necessidade de segurança, reconhecendo a existência de um ser superior, através do qual se busca a certeza das coisas, a harmonia social suficiente para uma vida tranqüila. A correlação deste valor com a intenção de constituir família sugere que esta pode promover sentimentos de segurança e proteção. Além disso, mesmo sendo considerado um valor que independe de preceito religioso, suas legendas pressupõem crença e obediência a Deus. Talvez isto explique o fato da maioria dos respondentes $(73,4 \%)$ pretender 
legitimar a união através de matrimônio civil e religioso. Igualmente, guiar-se pela religiosidade, na maioria das culturas ocidentais, implica aceitar uma orientação católicacristã, que sugere a constituição da família e a harmonia entre todos os seus ascendentes e descendentes.

Por fim, o valor estabilidade pessoal representa parcialmente a necessidade de segurança (ter certeza de que amanhã terá tudo o que tem hoje; ter uma vida organizada e planificada). As pessoas que priorizam este valor como princípio-guia em suas vidas, procuram assegurar sua própria existência, acentuando uma vida organizada e planejada. Sua correlação com a intenção de constituir família indica que as organizações familiares são vistas como uma instituição na qual pode-se assegurar o planejamento e a estabilidade na vida.

Concluindo, embora não retrate todos os aspectos específicos das variáveis envolvidas, em termos gerais, é possível dizer o seguinte: os jovens que buscam uma vida tranqüila, organizada e planejada, estabelecendo relações interpessoais seguras e satisfatórias, além de valorizar, nessas relações, o comprometimento e o envolvimento, apresentam maior intenção de constituir família. Isto ocorre naquele período que, na sociedade em que vivem, tem sido crítico para tal decisão, isto é, aproximadamente a partir dos 28 anos (IBGE, 1997a, 1997b).

Sugere-se que este estudo seja replicado com uma população que, além de ter a intenção de constituir família, o está fazendo de fato através do casamento civil. Por exemplo, poder-se-ia verificar se as variáveis encontradas neste estudo como explicativas da intenção de constituir família se confirmam na população de noivos (Fernandes, 2000).

\section{Referências}

Albornoz, S. (1983). Refletindo sobre a família hoje. Educação e Realidade, 2, 103-107.

Anastasi, A. \& Urbina, S. (2000). Testagem psicológica. Porto Alegre: ArtMed.

Azzi, R. (1987). Família e valores na sociedade brasileira numa perspectiva histórica (1870-1950). Sintese, 41, 87-109.

Bell, N.W. \& Vogel, E.F. (1963). Toward a framework for functional analysis of family behavior. In N.W. Bell \& E.F. Vogel (Eds.), $A$ modern introduction to the family (pp.1-33). Glencoe, NY: The Free Press.

Biaggio, A.M.B. (1996). Self e moralidade. In Z. Trindade \& C. Camino (Eds.), Cognição social e juízo moral. Coletâneas da ANPEPP, 6, 77-91.

Bystronski, B. (1991). A liberação dos costumes e suas conseqüências sobre os relacionamentos amorosos heterossexuais. Dissertação de Mestrado não-publicada, Curso de Pós-Graduação em Psicologia do Desenvolvimento, Universidade Federal do Rio Grande do Sul. Porto Alegre, RS.

Cárdenas, R.E.C. (1996). La familia, el niño y los valores. Un estudio de etnografia familiar. Educação, 30, 38-54.

Carneiro, N.G.O. (1994). A família. Psicologia Argumento, 14, 11 26.

Clemente, M. \& Fernández, I. (1992). La medición de las actitudes. In M. Clemente (Ed.), Psicología social: Métodos y técnicas de investigación (pp.302-323). Madri: Eudema.
Espinosa, P. (2000). Razonamiento moral y conducta social en el menor. Tese de Doutorado não-publicada, Curso de PósGraduação em Psicologia, Universidade da Coruña. La Coruña, Espanha.

Féres-Carneiro, T. (1998). Casamento contemporâneo: O difícil convívio da individualidade com a conjugabilidade. Psicologia: Reflexão \& Crítica, 11, 379-394.

Fernandes, H.M.R. (2000). Encontro com noivos, uma atuação preventiva na vara de família no Recife. [Resumo]. In Associação Ibero-americana de Psicologia Jurídica (Ed.), Resumos de comunicações científicas, III Congresso Ibero-Americano de Psicologia Jurídica (p.7 1), São Paulo, SP.

Fleck, A.C. \& Wagner, A. (2003). A mulher como a principal provedora do sustento econômico familiar. Psicologia em Estudo, 8(número especial), 31-38.

Freixa, M. (1998). La familia. In J.M. Redon (Ed.), La bolsa de los valores. Materiales para una ética ciudadana (pp.143-156). Barcelona: Ariel.

Goldani, A.M. (1994). As famílias brasileiras: Mudanças e perspectivas. Cadernos de Pesquisa, 91, 7-22.

Goode, W.J. (1969). Revolução mundial e padrões de família. São Paulo: Companhia Editora Nacional.

Gouveia, V.V. (1998). La natureza de los valores descriptores del individualismo y del colectivismo: Una comparación intra e intercultural. Tese de Doutorado não-publicada, Curso de PósGraduação em Psicologia Social, Universidade Complutence de Madri. Madri, Espanha.

Gouveia, V.V. (2003). A natureza motivacional dos valores humanos: Evidências acerca de uma nova tipologia. Estudos de Psicologia, 8, 431-443.

Gouveia, V.V., Coelho, J.A.P.M., \& Vasconcelos, T.C. (1999). Autoimagem e relações interpessoais: Sua variação intracultural. [Resumo]. In Associação Brasileira de Psicologia Social (Ed.), Resumos de comunicações científicas, $10^{\circ}$ Encontro Nacional da Associação Brasileira de Psicologia Social (p.86). São Paulo: ABRAPSO.

Gouveia, V.V., Singelis, T.M., \& Coelho, J.A.P.M. (2002). Escala de auto-imagem: comprovação da sua estrutura fatorial. Avaliação Psicológica, 1, 49-59.

Gouveia, V. V., Vasconcelos, T.C., Queiroga, F., França, M.L.P., \& Oliveira, S.F. (2003). A dimensão pessoal da responsabilidade social. Psicologia em Estudo, 8, 3-9.

Gouveia, V.V., Singelis, T.M., Guerra, V.M., Santos, W.S., \& Vasconcelos, T.C. (2005). Auto-imagem e sentimento de constrangimento. Psico, 36, 231-241.

Hardin, E.E., Leong, F.T.L., \& Bhagwat, A.A. (2004). Factor structure of the self-construal scale revisited: Implications for the multidimensionality of self-construal. Journal of CrossCultural Psychology, 35, 327-345.

Hofstede, G. (1984). Culture's consequences: International differences in work-related values. Beverly Hills, CA: Sage.

Instituto Brasileiro de Geografia e Estatística (1997a). Anuário estatístico do Brasil. Rio de Janeiro: IBGE.

Instituto Brasileiro de Geografia e Estatística (1997b). Contagem da população de 1996. Rio de Janeiro: IBGE.

Jablonski, B. (1996). Papéis conjugais: Conflito e transição. In T. Féres-Carneiro (Ed.), Relação amorosa, casamento, separação $e$ terapia de casal (pp.113-123). Rio de Janeiro: ANPEPP.

Jablonski, B. (1998). Até que a vida nos separe: A crise do casamento contemporâneo ( $2^{\mathrm{a}}$ ed.). Rio de Janeiro: Agir.

Kagitçibasi, Ç. (1994). A critical appraisal of individualism and collectivism: Toward a new formulation. In U. Kim, H.C. Triandis, Ç. Kagitçibasi, S.-C. Choi, \& G. Yoon (Eds.), Individualism and collectivism: theory, method, and applications (pp.52-65). Thousand Oaks, CA: Sage. 
Kagitçibasi, Ç. (1996). The autonomous-relational self: a new synthesis. European Psychologist, 1,180-186.

Kuhn, M.H., \& McPartland, T.S. (1954). An empirical investigation of self-attitudes. American Sociological Reviere, 19, 68-76.

Lasch, C. (1987). O mínimo eu: sobrevivência psíquica em tempos difíceis. São Paulo: Brasiliense.

Lay, C., Fairlie, P., Jackson, S., Ricci, T., Eisenberg, J., Sato, T., Teeäär, A., \& Melamud, A. (1998). Domain-specific allocentrismidiocentrism: a measure of family connectedness. Journal of Cross-Cultural Psychology, 29, 434-460.

Löhr, S. S., \& Wasch, E. (1992). E a “família brasileira”?. Psicologia Argumento, 12, 17-22.

Lima, M.L.P. (1996). Atitudes. In J. Vala, \& M.B. Monteiro (Eds.), Psicologia social (2 ${ }^{\text {a }}$ ed., pp. 167-199). Lisboa: Fundação Calouste Gulbenkian.

Macedo, R.M.S., Cerveny, C.M.O., Berthoud, C.E., Sudbrak, M.F., Costa, L.F., Moré, C.L.O., Lopes, R.C.S., \& Bromberg, M.H.P.F. (2000). Família e comunidade. In R.S.L. Guzzo (Ed.), Anais do VIII Simpósio Brasileiro de Pesquisa e Intercâmbio Científico (pp.206-211). São Paulo: ANPEPP.

Maia, L.M. (2000). Prioridades valorativas e desenvolvimento moral: Considerações acerca de uma teoria dos valores humanos. Dissertação de Mestrado não-publicada, Curso de Pósgraduação em Psicologia Social, Universidade Federal da Paraíba. João Pessoa, PB.

Markus, H.R., \& Kitayama, S. (1991). Culture and the self: implications for cognition, emotion and motivation. Psychological Review, 98, 224-253.

Maslow, A. (1954). Motivation and personality. New York: Harper \& Row.

Meira, M., Gouveia, V.V., Maia, L.M., Nunes Jr., J., \& Andrade, J.M. (2001, maio). Tipos motivacionais e valores humanos básicos: Convergência de dois modelos. Trabalho apresentado no II Encontro Norte-Nordeste de Psicologia, Salvador, BA.

Milfont, T.L. (2001). A intenção de contituir família: Suas bases normativas e relacionais. Dissertação de Mestrado não-publicada, Curso de Pós-graduação em Psicologia Social, Universidade Federal da Paraíba. João Pessoa, PB.

Milfont, T.L. (2005). Estrutura fatorial da Escala de Auto-Imagem: testando modelos alternativos. Estudos de Psicologia (Campinas), 23(3), 277-290.

Milfont, T.L., Gouveia, V.V., Jesus, G.R., Gusmão, E.É.S., \& Chaves, S.S.S. (2001). Estrutura fatorial da escala de atitudes frente a relacionamentos afetivos estáveis. [Resumo]. In Conselho Regional de Psicologia - $13^{\mathrm{a}}$ Região (Ed.), Resumos de comunicações científicas, I Encontro Paraibano de Avaliação e Medida (pp.22-23). João Pessoa: CRP.

Milfont, T.L., Gouveia, V.V., Chaves, S.S.S., Socorro, T.C., \& Queiroga, F. (2002). Valores humanos e auto-imagem: padrões de convergência e evidências de especificidades. Psico, 33, 427446.

Molpeceres, M.A. (1994). El sistema de valores: Su configuración cultural y su socialización familiar en la adolescencia. Tese de Doutorado não-publicada, Curso de Pós-graduação em Psicologia, Universidade de Valência. Espanha.

Montmollin, G. (1985). El cambio de actitud. In S. Moscovici (Ed.), Psicología social I (pp.117-174). Barcelona: Paidós.

Neder, G. (1994). Ajustando o foco das lentes: um novo olhar sobre a organização das famílias no Brasil. In S.M. Kaloustian (Ed.), Família brasileira, a base de tudo (pp.26-46). São Paulo: Cortez.

Oishi, S., Schimmack, U., Diener, E., \& Suh, E.M. (1998). The measurement of values and individualism-collectivism. Personality and Social Psychology Bulletin, 24, 1177-1189.
Osório, L.C. (1996). Família hoje. Porto Alegre: ArtMed.

Pinheiro, A.A.A., \& Tamayo, A. (1987). Urbanização, sexo e solidão: uma abordagem empírica. Psicologia: Teoria e Pesquisa, 3, 52-63.

Prado, D. (1989). O que é família ( $11^{\mathrm{a}}$ ed.). São Paulo: Brasiliense. Reis, B.F. (1995). Uma escala de atitudes frente a relações afetivas estáveis. Psicologia: Teoria e Pesquisa, 11, 67-71.

Rodrigues, A., Assmar, E.M.L., \& Jablonski, B. (2000). Psicologia social. Petrópolis: Vozes.

Rokeach, M. (1973). The nature of human values. New York: Free Press.

Sacareno, C. (1997). Sociologia da família. Lisboa: Estampa.

Sato, T. \& Cameron, J.E. (1999). The relationship between collective self-esteem and self-construal in Japan and Canada. Journal of Social Psychology, 139, 426-435.

Schneider, J.O. (2001). Transmissão de valores de pais para filhos: Dimensões do desejável e do perceptível. Dissertação de Mestrado não-publicada, Curso de Pós-graduação em Psicologia Social, Universidade Federal da Paraíba. João Pessoa, PB.

Schwartz, S.H. (1990). Individualism-collectivism: critique and proposed refinements. Journal of Cross-Cultural Psychology, 21, 139-157.

Schwartz, S.H. (1994). Are there universal aspects in the structure and content of human values?. Journal of Social Issues, 50, 1945 .

Singelis, T.M. (1994). The measurement of independent and interdependent self-construals. Personality and Social Psychology Bulletin, 20, 580-591.

Singelis, T.M. \& Brown, W.J. (1995). Culture, self, and collectivist communication: Linking culture to individual behavior. Human Communication Research, 21, 354-389.

Singelis, T.M. \& Sharkey, W.F. (1995). Culture, self-construal and embarrassability. Journal of Cross-Cultural Psychology, 26, 622-644.

Sinha, D. \& Tripathi, R.C. (1994). Individualism in a collectivist culture: a case of coexistence of opposites. In U. Kim, H.C. Triandis, Ç. Kagitçibasi, S.-C. Choi, \& G. Yoon (Eds.), Individualism and collectivism: theory, method, and applications (pp.123-136). Thousand Oaks, CA: Sage.

Tamayo, A. \& Schwartz, S.H. (1993). Estrutura motivacional dos valores humanos. Psicologia: Teoria e Pesquisa, 2, 329-348.

Thomas, W.I. \& Znaniecki, F. (1918/1984). The polish peasant in Europe and America. Illinois: University of Illinois Press.

Trafimow, D., Triandis, H.C., \& Goto, S.G. (1991). Some tests of the distinction between the private self and the collective self. Journal of Personality and Social Psychology, 60, 649-655.

Triandis, H.C. (1994). Cultural and social behavior. New York: McGraw-Hill.

Triandis, H.C. (1995). Individualism and collectivism. Boulder: Westview Press.

Veiga, A. (200 1, 25 de julho). Solidão. Lição de Casa: Aprender a viver só. Veja, 29, 102-108.

Wagner, A., Falcke, D., \& Meza, E.B.D. (1997). Crenças e valores dos adolescentes. Psicologia: Reflexão E Crítica, 10, 157-169. 